\title{
Medios de comunicación y crisis de representación política
}

MaRÍa DE la LUZ CASAS*

Resumen. Actualmente los medios de comunicación ejercen una función muy importante en México: por un lado, son fundamentales para el ejercicio de la crítica y por otro, su función es primordial en la conformación de nuevos espacios de gestación para la opinión pública. No obstante, bay que recordar que si bien su papel es sustantivo para el desarrollo democrático del país, su actuar no es autónomo ni independiente de sus propios intereses, ni de otras condiciones sociopoliticas o culturales vividas en el país en los ültimos años; por el contrario, responde al proceso mismo de democratización de la sociedad mexicana que ba traido como resultado un reacomodo de las posiciones de poder que anteriormente detentaban ciertos actores sociales, a un vacio de representación politica, de credibilidad y confianza en las instituciones y en las autoridades de gobierno.

Este trabajo apunta hacia el análisis de las condiciones actuales de los medios de comunicación en México dentro del marco de una sociedad en vias de democratización que muestra todavia señales de autoritarismo, para explicar que, de manera consustancial a otros procesos que se generan en sociedades democráticas en vías de desarrollo, las estructuras sociales y politicas sufren procesos de reacomodo que conducen a crisis de representación politica. En este proceso, son los medios de comunicación quienes pasan a ocupar los vacios de poder ejercitando su función fundamentalmente a través de dos vias: por un lado, justificando su actuar desde el propio sentido de la apertura informativa en una sociedad democrática y por otro, a través de una aparente transparencia informativa que desnuda a las organizaciones politicas y gubernamentales frente al ciudadano y refuerza su falta de credibilidad bacia las instituciones.

"Especialista en comunicación y política y en comunicación y nuevas tecnologías. ITESM, Campus Cuernavaca. Correo electrónico: marilu.casas@itesm.mx 


\section{Introducción}

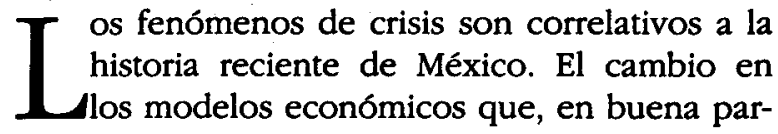

te hizo presión sobre los sistemas de gobierno hacia la apertura informativa, junto con la recuperación del espíritu democrático perdido durante tantas décadas de autoritarismo, gestaron poco un nuevo clima en nuestro país en el que destacan los medios como actores importantes de la política.

Actualmente los medios de comunicación ejercen una función muy importante en nuestro país: por un lado, son fundamentales para el ejercicio de la crítica y por otro, su función es primordial en la conformación de nuevos espacios de gestación para la opinión pública. No obstante, hay que recordar que si bien su papel es sustantivo para el desarrollo democrático del país, su actuar no es autónomo ni independiente de sus propios intereses, ni de otras condiciones sociopolíticas o culturales vividas en el país en los últimos años; por el contrario, responde al proceso mismo de democratización de la sociedad mexicana que ha traído como resultado un reacomodo de las posiciones de poder que anteriormente detentaban ciertos actores sociales, a un vacio de representación política, de credibilidad y confianza en las instituciones y en las autoridades de gobierno, y en otras características que veremos más adelante.

Es menester destacar que, independientemente de su papel en la conformación de una nueva cultura democrática, hoy nuestra sociedad parece otorgarle a los medios una especial importancia. Es por ello que se hace necesaria una crítica reflexiva en torno a su actividad, particularmente dentro del contexto de su operación y de las condiciones políticas, económicas y sociales que privan en nuestro país en estos momentos.

Así pues, el presente trabajo de investigación abordará el papel de los medios de comunicación en la sociedad mexicana partiendo de las siguientes premisas: primero, que México vive un fenómeno de transición a la democracia en el cual nuestra sociedad todavía presenta rasgos autoritarios, y segundo, que lejos de estar cumpliendo su papel fundamental, los medios se encuentran llenando un vacío de poder y de vinculación entre gobernantes y gobernados, y que su participación, lejos de mejorar esta relación, ha venido a enturbiarla (Casas, 2000 y 2003).

\section{Medios de comunicación y democracia}

La participación activa de los medios de comunicación en asuntos de política, particularmente en sociedades de régimen democrático, pudiera parecer natural y hasta deseable. No obstante, y precisamente a fin de 
ilustrar el contexto particular en el que se desenvuelve la política en nuestro país en estos momentos, es menester analizar en qué punto se encuentran los medios de comunicación respecto de la posición que ocupan otros actores sociales y políticos que tradicionalmente ocupaban posiciones importantes de poder.

Varias encuestas revelan que los mexicanos no creen o creen muy poco en la clase política, y a los políticos les alarma esta percepción porque consideran que se pone en riesgo el proceso de transición a la democracia en un país en el que hasta 2000 fue gobernado durante 71 años por un solo partido, el PRI. ${ }^{1}$

Como indicó el coordinador del PRI en la Asamblea Legislativa del Distrito Federal Manuel Jiménez, de acuerdo con la más reciente encuesta nacional Confianza en las instituciones, los diputados, tanto locales como federales obtuvieron una pésima calificación de apenas 4.2 en una escala de 10 puntos. $^{2}$ Así, los legisladores son los funcionarios a los que menos confianza les tienen los mexicanos.

De 12 dependencias evaluadas, siete obtuvieron notas reprobatorias; mientras que de los "aprobados", la Iglesia es la instancia que logra la mejor calificación con 7.7. En la segunda posición se encuentra el Ejército, con 7.5; seguido por los medios de comunicación, con 7; el Instituto Federal Electoral, 6.7, y el Presidente de la República con 6.1.

De los reprobados, la Suprema Corte obtuvo 5.7 de calificación; los empresarios, 5.3; la policía, 5; los sindicatos, 4.8; los senadores, 4.7, y los partidos políticos $4.7 . .^{3}$

Estos datos indican claramente cambios en la cultura política nacional, ya que actores sociales de importancia para la credibilidad de las instituciones de gobierno, han variado su posición en el monto de confianza que inspiran en sus ciudadanos. ${ }^{4}$

El hecho de que los medios de comunicación hayan ascendido en su posición de credibilidad en relación a otros actores de la política muy por encima de los partidos, los legisladores, los empresarios y los sindicatos, nos obliga a pensar en que la ciudadanía está trasladando espacios de poder anteriormente institucionalizados a ámbitos informales de influencia dentro de los cuales se encuentran los medios.

${ }^{1}$ (Sin autor), "Crisis de credibilidad política paraliza a México", en Terra, Noticias len línea]. Disponible en: http://terra.com/actualidad/articulo/html/act176002.htm. Consultado el 12 de mayo de 2004.

2 (Sin autor), "Hay poca credibilidad hacia la política: PRI", en El Economista len línea]. Disponible en http://economista.com.mx/online4.nsf. Consultado el 1 de junio de 2004.

3 Olivier Pavón, "En índice de 'confianza', la policía sale reprobada con 5 puntos; los diputados sacan sólo 4.2: encuesta Mitofsky", en Crónica [En línea]. Disponible en: http:// www.cronica.com.mx/nota.php?idc=124593. Consultado el 2 de junio de 2004.

1 Hay que recordar que dos de las caracteristicas fundamentales de los regímenes democráticos son el respeto del Estado de derecho y la confianza en las instituciones de gobierno. 
En este mismo tenor encontramos que, de acuerdo con una encuesta realizada por la Dirección Ejecutiva de Capacitación Electoral del Instituto Federal Electoral, los medios de comunicación ocupan el sexto lugar en el índice de credibilidad de la ciudadanía, sólo por debajo de las iglesias, los maestros, los hospitales, el IFE, y la Comisión Nacional de Derechos Humanos.

Datos relativos a este aspecto dentro de este mismo estudio concluyen que, por debajo de la confianza que inspiran los medios de comunicación, se encuentran el gobernador o jefe de gobierno, el Presidente de la República, las empresas, el Presidente Municipal, las agrupaciones de ciudadanos, la Suprema Corte de Justicia, las secretarías de Estado, las organizaciones no gubernamentales, los sindicatos, las cámaras de diputados y senadores, y en último lugar, los partidos políticos. ${ }^{5}$

El papel de los medios de comunicación es, por tanto, esencial, no sólo en la conformación de una nueva cultura política para los mexicanos, sino que también en la distribución de imaginarios específicos de realidad que permiten la generación de escenarios posibles, particularmente en situaciones de crisis como las que ha vivido nuestro país en su historia reciente.

\section{Generación de expectativas y generación de demandas sociales}

Ahora bien, a fin de analizar con mayor precisión el comportamiento específico de los medios de comunicación, en este trabajo abordaremos dos cuestiones fundamentales: por un lado, la estructura discursiva dominante en la política mexicana reciente y por el otro, el manejo de la opinión pública desde la articulación de la transparencia informativa.

$\mathrm{Si}$ bien este fenómeno viene gestándose en nuestro país desde hace décadas, el papel predominante de los medios en la gestión política ha cobrado su ejemplo más puntual a últimas fechas, a partir de una situación específica relativa a asuntos de corrupción, ${ }^{6}$ la cobertura de medios escala vinculando la agenda nacional con la internacional, relacionando cuestiones de política doméstica con asuntos de política exterior, e involucrando a la opinión pública nacional e internacional en todo el proceso.?

5 Noemí Luján (2002), "Credibilidad y confianza políticas: elementos para un diagnóstico de la cultura política en México", resultados presentados por la Dirección Ejecutiva de Capacitación Electoral del Instituto Federal Electoral en el "Coloquio para el análisis de encuestas nacionales sobre cultura politica y prácticas ciudadanas", sitio del DECEYEC. IFE [en linea]. Disponible en: http://deceyec.ife.org.mx/credibilidad_confianza.pdf. Consultado el 12 de mayo de 2004.

6 (Sin autor), "Hay poca credibilidad hacia la política: PRI", en El Economista [en línea]. Disponible en: http://economista.com.mx/online4.nsf. Consultado el 1 de junio de 2004.

${ }^{7}$ Es a través de dar a conocer a la opinión pública por medio de videos transmitidos en 
Este problema, no es un problema exclusivo de nuestro país, sino que es característico de sociedades emergentes cuyo grado de desarrollo democrático es todavía incipiente, combinado con vestigios de autoritarismo, como el caso de México. ${ }^{8} \mathrm{De}$ hecho, las formas tradicionales de gobierno están cambiando en todo el mundo.

Como bien indica Restrepó, la apertura a nuevos modelos de crecimiento, aunada a la ausencia en el cumplimiento de las expectativas de desarrollo por parte de la ciudadanía precipitó una crisis de la institucionalidad política en niveles nunca antes vistos (Restrepó, 2003: 16-19), una rebelión en contra de las formas autoritarias de gobierno que, en el caso de México, debilitó las prácticas corporativas existentes, facultó un cambio de régimen y propició una participación más sistemática por parte de la sociedad civil. ${ }^{9}$

Podemos ver entonces, que los sistemas tradicionales de representación ya no responden a las necesidades de sociedades globales, y que las estructuras institucionales tampoco son adecuadas a las demandas de transformación política contemporáneas. Esto ha generado una cierta incapacidad en los gobiernos para responder a las demandas sociales o gobiernos de baja capacidad.

Un gobierno de baja capacidad, según Aguilar, es el resultado de dos eventos del fin del siglo pasado: la crisis y el ajuste. La crisis dejó en claro a los ciudadanos (no así a la clase política) que el gobierno había llevado al desastre a su sociedad, que no la había dirigido sino al abismo; por lo tanto, una de las características de los periodos de crisis es la pérdida de credibilidad de la ciudadanía respecto de sus gobernantes (Aguilar, 2004: 18).

El segundo factor es la pérdida de capacidad directiva del Estado, y su incapacidad para generar consensos como resultado de las políticas obligadas de ajuste para salir de la crisis. El adelgazamiento del Estado le hizo perder facultades, capacidades, activos, y alcances a favor de los mercados privados y las organizaciones sociales.

Un tercer elemento es la democratización misma, ya que en tiempos pasados el Estado había sido el centro de la conducción política. De hecho, el resultado neto de estos cambios fue poner un punto final no sólo al modo de gobernar del siglo $\mathrm{xx}$ sino a los alcances del gobierno. ${ }^{10}$ Así, las condicio-

cadena nacional por los medios de comunicación, que comienza á darse todo el escándalo. En lugar de que los actores políticos involucrados asistiesen directamente a las instituciones de justicia a demandar el hecho, éste se ventila primero en los medios.

${ }^{8}$ Nos referimos específicamente a la serie de videos que dieron cuenta de la corrupción en asuntos de gobierno, comenzando con el video del "Niño Verde" hasta terminar con el caso Ahumada y el enfriamiento de nuestras relaciones diplomáticas con Cuba.

- Así, por ejemplo, vemos cómo, en el caso de Cuba, los medios siguen siendo utilizados como vehículos de propaganda y son llamados a definir la situación de la relación con México.

${ }^{10}$ La encuesta más reciente del Consorcio Iberoamericano de Investigación y Mercadeo (CIA) indica que en los principales países de América Latina, entre los que se encuentran 
nes globales de falta de representatividad, incremento en las demandas sociales y los problemas internacionales de alcance global han provocado que los gobiernos tengan cada vez más dificultades para gobernar.

La novedad de la política contemporánea es centrar todos los problemas alrededor de la eficacia directiva de los gobiernos, que han sido creados justamente para dirigir a sus sociedades. El énfasis en la eficacia gubernativa de los gobiernos puede ser considerado como algo parcial, algo sesgado, pero es la expectativa social principal respecto de los gobiernos. O el gobierno es eficaz o es una contradicción andante, socialmente inservible o, peor, es factor de desgobierno. Una democracia vale por ser libremente elegida y representativa, pero si no es eficaz y no arroja resultados es simplemente un gobierno sin capacidad de gobierno y empieza a erosionar su valor social. ${ }^{11}$

Como bien apunta Norris: conforme las sociedades contemporáneas evolucionan, tienden a aparecer nuevas formas de participación política que la ciudadanía practica con intensidad creciente, tales como: promoción de intereses particulares, de grupo o difusos, cartas a medios de comunicación, audiencias con funcionarios, escritos de propuesta y/o demanda a la autoridad, movilizaciones sociales, manifestaciones de protesta, plantones y similares, más allá de recurrir a los canales tradicionales de participación política. ${ }^{12}$

Así pues, en situaciones de crisis, los medios de comunicación ejercen una función doble: por un lado, dan a conocer las particularidades de la crisis y en ese mismo sentido contribuyen no solamente a difundirla sino también a ampliarla, y por otro, pasan a ocupar los espacios de representación que dejan libres las instituciones políticas.

Lo anterior nos permite observar una tendencia creciente hacia la bipermediatización de la política, en donde la comunicación se utiliza como una interfase entre lo político y la información que poco a poco genera un proceso que termina desvirtuando lo político a partir de lo mediático, y en donde lo mediático termina reemplazando a lo político (Winocur, 2000: 77).

Brasil, Venezuela, México, Chile, Perú, Argentina, Colombia, Guatemala, Bolivia y Ecuador, de 75 a $90 \%$ de los ciudadanos encuestados desconfía de los partidos políticos, mientras que entre 70 y $90 \%$ no cree en los congresos locales. Encuesta cima Consorcio Iberoamericano de Investigación y Mercadeo (febrero de 2003), Revista Semana de Bogotá, núm. 1086 del 24-02-03, pp. 44 y sig, citado en Javier Darío Restrepó, "La palabra y la democracia", Suplemento Enfoque, Reforma, 6 de julio de 2003, pp. 16-19.

11 Restrepo (2003), pp. 16-19.

12 Norris, Pipa, "El involucramiento cívico: México desde una perspectiva comparada", conferencia magistral impartida en la Secretaría de Gobernación durante el Coloquio para el análisis de encuestas nacionales sobre cultura política y prácticas ciudadanas, 2001, Secretaria de Gobernación len línea]. Disponible en: www.gobernacion.gob.mx/coloquio/ Abs/05\%20Norris.htm. Consultado el 2 de junio de 2004. 
$\mathrm{Y}$ es que los estados contemporáneos apoyan buena parte de su actuación política en los medios, de manera que terminan en una trampa doble: por un lado sirviéndose de los medios, y por otro, atendiendo no sólo a las presiones de información de los mismos medios, sino también a las demandas internas y externas de la opinión pública. ${ }^{13}$

Este fenómeno supone una situación contraria al comportamiento que normalmente se esperaría por parte de los medios de comunicación en una sociedad democrática. Esto es, se habla mucho de que el costo de la democracia implica asumir, necesariamente, los costos de la libertad de expresión irrestricta. Sin embargo, sabemos que si bien la búsqueda de la democracia debe ser un proceso constante, la existencia de información amplia y variada a través de los medios de comunicación no necesariamente implica que el proceso democrático ha sido exitoso; antes bien, demuestra que el dejar todo el proceso de vinculación de los actores políticos con la ciudadanía en manos de los medios, puede ser condición suficiente para sospechar una crisis de representación de las instituciones políticas. A la larga, este fenómeno puede no solamente opacar el proceso de consolidación de la democracia, sino incluso frenarla.

No obstante, no todo lo anterior es responsabilidad de los medios, más bien es sintomático de una relación que no se encuentra en la mejor de sus expresiones. Las formas de convivencia, la estructura y significación de los discursos de la política forman parte de la relación entre el político, la actividad política y el ciudadano. En ese sentido, los medios no hacen sino ubicarse en los vacios intermedios, no llenados por la relación natural entre el político y la ciudadanía.

Ante un vacío de información, el medio buscará generar la información propia que dé contexto a lo sucedido. La combinación de las informaciones presentadas dará como resultado el imaginario político predominante para una situación dada. Así pues, el papel de los medios de comunicación es especialmente importante; sobre todo en escenarios de crisis o de transformación política. Su actuación como gestores de escenarios de futuro puede ser también, por tanto, indicativa de las crisis de representación que se nos aparecen hoy en día como producto de un mundo complejo y convulsionado.

${ }^{13}$ La Cancillería mexicana se enteró primero por los medios de comunicación de la decisión del gobierno cubano de deportar al empresario Ahumada Kurtz, antes que recibir una respuesta oficial a la petición formal de México de iniciar un juicio de extradición. Este incidente, entre otras cosas, propició la decisión del gobierno mexicano de retirar a su embajador en Cuba y solicitar el retiro del embajador cubano en México, lo cual originó un fuerte conflicto diplomático. El ir y venir de declaraciones en los medios, tanto en un país como en otro, complicó aún más la situación, al grado de que llegó el momento en el que incluso el gobierno mexicano pidió al gobierno cubano no dirimir este asunto a través de los medios, sino por el contrario, restringirse a utilizar los canales diplomáticos (Infosel financiero, 4 de mayo de 2004). 
¿Hasta qué punto los medios de comunicación son responsables, a partir de una cobertura mediática, de ampliar el conflicto entre los asuntos domésticos de la política nacional mexicana para ampliarlos a la esfera de la diplomacia? ¿Hasta qué punto los políticos hacen uso de los medios de comunicación para externar sus posiciones ideológicas y son rebasados por la acción propia de los medios?

Por supuesto que el papel de los medios de comunicación es fundamental para lograr una buena difusión de las propuestas y de las posiciones políticas. Como dice Thompson:

El uso de los medios de comunicación transforma la organización espacial y temporal de la vida social, creando nuevas formas de acción e interacción, y nuevos modos de ejercer el poder, los cuales ya no están ligados a compartir una ubicación común [Thompson, 1995: 4].

De tal suerte, los medios de comunicación expanden fronteras, promueven el conocimiento de temáticas que no estarían de otro modo al alcance de los ciudadanos y ponen asuntos en la agenda pública para su discusión. No obstante, tendríamos que extender nuestra definición para, en un sentido más amplio, reconocer que los medios vinculan no solamente con nuestra realidad inmediata, sino, también, con otras realidades circundantes.

El mundo moderno se conforma a partir de esquemas nuevos de convivencia. Los estados-nación ya no son las estructuras políticoeconómicas o ideológico-sociales que estaban listas para contener las aspiraciones de pueblos con deseos de marcar diferencias en términos de territorialidad, religión o lengua. Por el contrario, hoy en día vemos naciones que, ansiosas de compartir los beneficios de la abundancia que prometen las economías de bloque, comprometen $\mathrm{o}$, en todo caso, negocian la soberanía que otrora fuese funcional como germen de la modernidad que procrea al Estado democrático actual (Habermas, 1989).

¿Dónde queda, pues, lo público? ¿Dónde se encuentran los espacios de la nación y de lo nacional? En sociedades como la nuestra, y como muchas otras de las sociedades latinoamericanas que luchan por su desarrollo, los pocos espacios públicos en donde es posible observar el alma de la nación se encuentran en la plaza y en los mercados públicos, en las aceras de las calles, en los parques y en las paradas de autobús.

Por lo que respecta a la clase media y alta, los espacios de lo público están siendo ampliados para incluir el mall, las páginas del Internet y otros espacios mediáticos; de tal manera que podríamos decir que la nación se encuentra dividida, la discusión segmentada y que lo público está siendo invadido por lo privado o viceversa, transformando así todo el espacio de la discusión de la agenda pública. 
En México, hoy en día quienes se interesan por la política pertenecen a un segmento muy reducido de la población. Los viejos actores de la política son los que siguen participando; la realidad es que los medios de comunicación han vacunado a las generaciones jóvenes respecto de su participación en política.

Desde luego, no hay datos específicos por el momento que puedan avalar esta sospecha, sin embargo, la información de la que se dispone parece apuntar, desde distintas perspectivas, precisamente en esa dirección. Así por ejemplo, según la última Encuesta Nacional de la Juventud, la política no está entre las actividades prioritarias de los jóvenes. En dicha encuesta $80 \%$ de los jóvenes declaró hablar poco o nada de política con sus padres, y $90 \%$ dijo hablar poco o nada con sus amigos. Noventa y cuatro por ciento respondió que definitivamente no confía en los políticos y $54 \%$ dijo confiar poco. En esta encuesta también los políticos resultaron ser los segundos personajes en los que menos confían los jóvenes, precedidos de los judiciales. ${ }^{14}$

Los resultados muestran que la población joven es más corrupta, ya que en los hogares en los que el jefe del hogar es menor a 50 años hay mayor corrupción que en aquéllos en los que el jefe de familia es mayor de esa edad, y que los jefes de hogar con mayor escolaridad en promedio dieron más "mordidas" que aquéllos que tienen menor escolaridad; 15 lo cual indica que no necesariamente a mayor escolaridad menor corrupción.

Este dato es especialmente preocupante, si se toma en consideración que la esperanza de la democracia radica justamente en la concientización y en la participación de la ciudadanía en asuntos de gobierno; y que quizás la denuncia y la presentación irrestricta de actos de corrupción política en los medios de comunicación esté generando una especie de efecto de descrédito y cinismo hacia la política en las generaciones jóvenes.

Pensar que la proliferación de los medios de comunicación -especialmente los nuevos-, permitiría un impulso mucho más acelerado a los movimientos democratizadores de las sociedades en desarrollo, es decir, que el medio funcionaría como vínculo entre los espacios privados de los sujetos y el espacio público, ha llegado a ser lugar común; sin embargo, nada hay más alejado de la realidad.

Estudios recientes sobre programas de radio y de televisión abiertos al público demuestran que la contribución de los medios a la transparencia y

14 Instituto Mexicano de la Juventud (2002). "Resultados de la Encuesta Nacional de la Juventud ${ }^{n}$ aplicada a jóvenes entre 12 y 29 años de edad a una muestra probabilística y estratificada por conglomerados a nivel nacional, Instituto Mexicano de la Juventud [en línea]. Disponible en: http://www.imjuventud.gob.mx/investigacion/encuesta.htm. Consultado el 2 de junio de 2004.

15 Organización Transparencia Mexicana [en línea]. Disponible en: http:// wwwtransparencia mexicana.org.mx/documentos/ENCBG\%202003/Encuesta\%20Nacional\%20 de $\% 20$ Corrupcion $\% 20$ y\%20 Buen\%20Gobierno\%202003.pdf. Consultado el 1 de junio de 2004 . 
democratización social es muy leve; que los sujetos que expresan su opinión no hacen sino defender sus puntos de vista sin escuchar los del otro, y que el modo de seleccionar y editar las opiniones por parte de los medios, convierte las demandas, quejas y catarsis en un discurso homogéneo que reproduce el orden social y los lugares comunes de la cultura política (Aguilar Díaz, 1996, en García Canclini, 1998). ${ }^{16}$

De tal suerte, el espacio público ha perdido su razón de ser de acuerdo a la tradición liberal democrática, y cuando mucho, está siendo utilizado como un espejo de lo privado, como la posibilidad de escuchar nuestros pensamientos en voz alta, pero sin que ellos nos lleven, necesariamente a la acción conjunta o comunitaria.

¿Cuál es el papel de los medios de comunicación en todo esto? ¿Cuál es el discurso o los discursos predominantes? ¿Cuál es el papel de los medios de comunicación en la conformación de la agenda pública, en la determinación de las necesidades políticas de un pueblo?

La premisa que defendemos aquí es que estamos frente a un discurso doble: un discurso que ensalza la globalidad y defiende a ultranza la nacionalidad, como si una no dependiera de la otra. La hipótesis es que los medios de comunicación colaboran en generar la ilusión de la transparencia democrática a través del discurso, pero que en realidad el discurso que llega al espacio privado de los sujetos no trasciende a la arena de lo público.

\section{El discurso mediático acerca de la política contemporánea}

Parte del problema que encontramos en la crisis de credibilidad que los ciudadanos expresan en relación a los políticos y a las instituciones de gobierno tiene que ver con la falta de resultados del ejercicio público.

Pese a que los políticos contemporáneos utilizan cada vez con mayor frecuencia los medios de comunicación para difundir sus propuestas y cultivar su imagen, pareciera ser que los mensajes de este tipo de comunicación política ya no están surtiendo el mismo efecto. Por el contrario, los medios de comunicación se han ganado la confianza de los receptores por su actitud de denuncia y exposición en torno de la corrupción y el desenfreno de los políticos.

De acuerdo con la Encuesta Nacional de Corrupción y Buen Gobierno 2003, elaborada por la organización Transparencia Mexicana, la corrupción le ha costado al país 10656 millones de pesos anuales en "mordidas" para recibir 38 servicios o para agilizar trámites de la administración

16 Aguilar Díaz, Miguel Ángel, "Espacio público y prensa urbana en la ciudad de México", en Perfiles Latinoamericanos, año 5, núm. 9, Flacso, México, diciembre de 1996, citado por Néstor García Canclini, "La globalización en pedazos: integración y rupturas en la comunicación", Diálogos de la Comunicación, núm. 51, año 98. 
pública. Los encuestados reconocieron participar en actos de corrupción debido a la crisis económica y a la pérdida del poder adquisitivo que los lleva a buscar economía de tiempo o dinero y debido a la ineficiencia gubernamental, ya que según indicaron la corrupción inicia en quien la pide y el sistema opera de esa manera. ${ }^{17}$ Lo anterior es coincidente con la visión que presentan los medios de comunicación al exponer la corrupción, lo cual viene a reforzar la idea preconcebida de la ciudadanía respecto a la ineficiencia gubernamental incrementando así la falta de credibilidad en las instituciones políticas.

El discurso predominante de los medios de comunicación hoy en día, al menos en México, parece no tener ya nada que ver con los ideales de la comunicación política. Estamos viendo un fenómeno discursivo que se empeña en alejar al sujeto de su participación política en lugar de promoverla; un discurso que segrega en lugar de buscar los consensos. Con el pretexto de que los medios deben de presentar una variedad de opiniones, el discurso se diluye dentro de la saturación de la información, aturde y aliena.

Para que la comunicación política rindiera verdaderamente los frutos que se esperan de ella, el discurso ha de ser institucionalizado por las instancias que entran en comunicación. Emisor y receptores, al igual que las condiciones en las que se gesta la comunicación (Habermas, 1998). Sin embargo, lo que estamos viendo es que la práctica periodística se ha convertido en todo, menos en un recurso de información fiable para la generación de opiniones y de consensos. En todo caso, es un arte: el arte de crear imágenes e ilusiones creíbles.

En opinión del historiador norteamericano Daniel J. Boorstin:

La producción de ilusiones que invaden nuestra experiencia se ha convertido en uno de los negocios más productivos. Esto es aplicable no solamente para los ámbitos de la publicidad, de la retórica y de las relaciones públicas, sino para toda aquella actividad que supuestamente nos informa, entretiene y educa. La mayor parte de los periodistas profesionales, editores de periódicos, de revistas y de libros, incluidos los políticos, hacen esfuerzos cotidianos para producir este tipo de ilusiones día con día [Boorstin, 1992:7].

Todas las sociedades que utilizan el estándar periodístico que emana de las industrias occidentales de medios, están en el negocio de la producción de ilusiones, ilusiones que satisfacen expectativas, pero que, al mismo tiempo, suprimen y suplen a la realidad en turno. La prensa no puede funcionar como interlocutor entre gobernante y gobernados y por

${ }^{17}$ Transparencia Mexicana (2003), "Encuesta Nacional de Corrupción y Buen Gobierno", Transparencia Mexicana len líneal, Disponible en: http://www.transparenciamexicana.org.mx/. Consultado el 1 de junio de 2004. 
lo tanto no puede funcionar como cuarto poder en la medida en que la realidad que maneja es ilusión y en la medida en que lejos de informar, desinforma. ${ }^{18}$

De acuerdo con J.M. Balkin los medios de comunicación, particularmente la televisión, simulan transparencia en su cobertura y, por ello, al mismo tiempo la subvierten a través de una estrategia muy simple: poner a la vista de todos los telespectadores los acontecimientos, pero alterando el contexto en el cual la gente ubica la información presentada (Balkin, 1998).

En otras palabras, en lugar de ocultar la información, el periodismo electrónico televisivo pone al descubierto la información, la presenta toda, incluso en exceso, sin dar elementos para su interpretación. De hecho, la información es tan vasta, que los ciudadanos sucumben ante los excesos reteniendo la anécdota, el detalle y cegados por la nota sensacionalista, dejan de descubrir la verdadera esencia de la información y su trascendencia. ${ }^{19}$

La relación entre los medios de comunicación y el público y los políticos y sus conciudadanos puede ayudar a explicar mejor cómo es que la estrategia de la transparencia puede ser útil a ambas instancias de poder. El medio de comunicación necesita mantener informado (entretenido) a su auditorio; así pues, la estrategia de la apertura y saturación en el detalle de la información se ve complementada con dos tácticas adicionales: distracción de la atención básica y suplantación de la realidad. El propósito fundamental es "distraer" acerca de los verdaderos propósitos y significación política de la información para ganar tiempo.

El tiempo es fundamental en política y es fundamental en el negocio de los medios masivos de comunicación. Hay que cubrir tiempo al aire compitiendo con otras tantas cadenas y canales informativos y de entretenimiento. Por lo tanto, tomando como base la información que se produce en el lugar de los hechos, hay que "estirar la nota", "escribir la historia" o "crear el acontecimiento."

is El mito de la objetividad periodística ha sido explorado por diferentes autores para demostrar que el hecho no es reportado de manera objetiva por el periodista en la medida en la que se presentan diversos agentes que sesgan el contenido de las informaciones. El famoso "gatekeeper" (1947) de Kurt Lewin es el ejemplo más claro de ello, pero también se han desarrollado análisis posteriores con otras metodologías, que muestran que el discurso de los medios es un discurso falaz que disfraza sus verdaderas intenciones bajo una máscara de objetividad. Al respecto véase ejemplo, Casas, 1997; Balkin, 1998.

${ }^{19}$ El caso más claro lo tuvimos en los video escándalos. ¿Qué puede haber más claro para la ciudadanía que ver con sus propios ojos cómo Ahumada le entregaba fajos de dinero a Bejarano o a Imaz?

20 Este último término "crear el acontecimento" fue acuñado por el argentino Eliseo Verón en su célebre estudio sobre la cobertura informativa que hicieron los medios estadunidense del accidente nuclear de Three Mile Island. Otros autores como Gale Tuchmann por ejemplo, han utilizado terminología similar para indicar que el periodista toma unos cuantos datos como referencia para la "creación de sus historias periodísticas". Todo lo anterior, desde luego, viene a reforzar la idea de que la objetividad en la información periodística no existe. 
Para el político, ganar tiempo también es fundamental. Se pueden incluir distintos puntos en la agenda política de acuerdo con las necesidades de negociación; también, se pueden incluir determinados argumentos a la agenda de la discusión, lograr espacios para el cabildeo, presentar puntos de vista en los medios de comunicación y facilitar la adhesión política. Una batalla en las cámaras puede ganarse o perderse de antemano en la arena del espacio público de los medios. ${ }^{21}$

Para los más conocedores se encuentran los programas de opinión y análisis. Ello permite apuntalar el mito de la transparencia política, agregando a la información presentada un cúmulo de opiniones de expertos que no necesariamente añaden datos nuevos o no conocidos a lo que se discute, pero que ejercen su liderazgo sobre la opinión pública. El presentar estos otros puntos de vista soporta la idea de que el medio está siendo objetivo e imparcial, pero al mismo tiempo subvierte la objetividad confundiendo al ciudadano acerca de lo que en realidad pasa por la mente de quienes se encuentran tomando las decisiones políticas.

Adicionalmente a lo anterior, los medios, han generado una nueva realidad en la que pululan una buena cantidad de comentaristas, editorialistas, analistas políticos, investigadores, encuestadores etcétera, que viven y se reconcilian no solamente con lo que pasa políticamente sino con lo que dicen otros que hablan sobre política, de manera que el medio se convierte en un espejo que se refleja a sí mismo. Analistas hablando sobre analistas, comentaristas comentando sobre los reportajes de otras cadenas, políticos opinando sobre la opinión de otros políticos y usando al medio como foro para hacer públicas sus posturas políticas. Nadie se encuentra hablando realmente de lo que está sucediendo, todos especulan sobre lo que sucedió o lo que está por suceder; y como la influencia de los medios es muy grande, las cosas eventualmente suceden y entonces toda una elite de expertos se regocija sobre su buen colmillo para el análisis político. Esto es lo que en opinión de Balkin se debe conocer como la autopredicción cumplida. ${ }^{22}$

Nuevamente, volvamos a la necesidad de restituir el vínculo de comunicación entre el gobernante y el gobernado. Es menester, por tanto, legitimar las fuentes y los canales de comunicación en la política.

21 Así lo demuestra por ejemplo la campaña excesiva que los medios mexicanos lanzaron en contra de la mal llamada Ley Mordaza relativa a la iniciativa de modificación de las leyes de comunicación que regulan la actividad de los medios de comunicación en México. Esta campaña se orquestó en los medios en tiempos políticos predeterminados mucho antes de que la iniciativa fuera presentada en el Senado de la República para su discusión, logrando con ello desanimar a varias fracciones parlamentarias con respecto de su aprobación. Así, los medios utilizaron el espacio público siendo juez y parte de la propia iniciativa que pretendía reglamentarlos e inclinaron la balanza en favor de los intereses empresariales y en contra de los grupos que pretendian regularlos.

22 En inglés self-fulfilling representation. 
Para que rinda frutos, la voluntad ciudadana puede gestarse a través de la participación política institucionalizada (partidos políticos), o bien, a través de expresiones públicas que alcancen la arena pública. Es a través de cualquiera de estos casos, que la comunicación vincula a quienes se enmarcan en el juego de la política, haciendo de su actuación un elemento sustantivo para el ejercicio de la democracia.

La posibilidad de un gobierno legítimo y creible se gesta, justamente en los espacios en los que se desarrolla la institucionalidad en el ejercicio del voto, pero también en los espacios informales en los que se crea la opinión pública. Esta relación, bien conocida tanto por las instituciones políticas como por los propietarios de los medios de comunicación, es cuidadosamente articulada para aprovechar los espacios de mediación de la política y las instituciones al punto de que "la lógica y la organización de los medios [especialmente los medios] electrónicos, encuadra y estructura a la política" (Castells, 1999: 344).

Desafortunadamente, lejos de cumplir esta noble tarea, los medios se empeñan en convertirse en los nuevos interlocutores de la gestión política, mediando la participación ciudadana, estableciendo los elementos esenciales de la agenda para la discusión pública, criticando al poder político en turno mucho antes de que los ciudadanos aprendan la práctica de la rendición de cuentas. Así, los medios de comunicación han trivializado el arte de la política traduciendo a propuestas partidistas y a candidatos por igual en productos de consumo; buscando capitalizar el escándalo a fin de asegurar la nota y el consumo del producto informativo.

En buena parte del mundo la comunicación política ha venido a sustituir a los viejos sistemas de interacción entre gobernantes y gobernados. Hoy, los medios de comunicación se han erigido no en los nuevos intermediarios de la acción política, sino en los nuevos actores de la política, sustituyendo así a quienes tenían ese papel fundamental en el desarrollo del proceso democrático.

En sociedades democráticas avanzadas, la actuación de los medios frecuentemente delimitada por un marco de legalidad es responsable del desarrollo simultáneo e independiente de diversos órdenes de realidad cuya articulación se traduce eventualmente en demandas sociales, culturales, políticas y económicas hacia el Estado. Sin embargo, en países en donde la democracia está en desarrollo, el problema es que las demandas sociales, económicas, políticas y culturales son cada vez más diversificadas y complejas. En esa situación, el Estado no puede cumplir ya a cabalidad con su función social y política ni dentro ni fuera de los límites de su constitución sistémica.

Una de las presiones más fuertes que recibe viene indiscutiblemente de los medios, ya que con el propósito de canalizar las demandas dando cabida a todas las voces, los medios de comunicación difunden buena parte de las promesas, de las propuestas, y en el mejor de los casos, de 
acciones, que se traducen en un discurso político poco creíble y cuando menos desordenado.

Esta incapacidad discursiva para responder con orden a las cuestiones elementales de su actuación pública, conduce a un estado de esquizofrenia en el cual parece decirse una cosa y se hace otra. La ausencia de propuestas, el desbalance de propósitos, la poca generación de compromisos por parte de los actores políticos en un contexto de transición y alternancia no resulta ser un mensaje digerible para la ciudadanía, como tampoco lo son las críticas que de avanzada propinan los medios de comunicación a todo el sistema en transición. La propuesta política poco clara que circula entonces a través de los medios de comunicación, poco ayuda a los escenarios de consolidación del poder y, desde luego, tampoco responde a las necesidades de información de una ciudadanía cada vez más crítica, cínica ante los resultados que se presentan.

Entonces, el escenario resultante se caracteriza por una falta de credibilidad hacia las instituciones políticas y hacia las bondades del sistema democrático; por lo que, lejos de fortalecerse, las instituciones políticas salen perjudicadas (aun aquellas que supuestamente deberían gozar del apoyo del electorado a fin de llevar a cabo su labor de representación ciudadana).

Como indica Touraine, la democracia es un régimen político cuyo funcionamiento está mediado por los tipos de articulación entre sociedad, sistema político y Estado existentes en una formación social, en un momento histórico determinado (Touraine, 1995). Los tipos, grados o formas que reviste la democracia dependerán en gran medida de los tipos de articulación establecidos entre los actores arriba mencionados.

En el caso de algunos países de América Latina, y particularmente en el caso de México, los patrones de articủlación entre sociedad, sistema político y Estado han sufrido transformaciones especialmente importantes vinculados al desplazamiento del Estado en favor de una participación más directa de otros agentes políticos, lo cual facilitó la transición de un modelo de desarrollo esencialmente estatal a uno dependiente de las fuerzas internacionales del mercado.

$\mathrm{Si}$ tomamos en consideración la situación internacional, veremos que en general los países en vías de democratizarse, como el nuestro, comparten condiciones que les obligan al desarrollo sostenido, independientemente de sus inconsistencias políticas.

Lo anterior nos lleva a concluir que, en México, los medios de comunicación han venido a sustituir a las viejas estructuras de representación política, haciendo a un lado a las instituciones establecidas y socavando desde sus raíces al Estado de derecho.

Como dice Aguilar Zínzer: 
México está deprimido. [...] Lo que le sucede al país no es la reacción de dolor o pérdida ante una desgracia especifica y tangible, no que haya habido un terremoto, o un gran ataque terrorista, tampoco una crisis financiera o una epidemia incontrolable. Lo que México vive es un desánimo profundo y contagioso, una crisis de confianza en nuestro destino e incluso en nosotros mismos. [Aguilar Zínzer, 2004: 19].

El problema es que esa crisis de confianza se retransmite a través de los medios de comunicación, se reproduce alimentando aún más la falta de credibilidad y empeorando la crisis. Como es bien sabido, si esa crisis de confianza se contagia a otras esferas puede transformarse en falta de confianza para la inversión, la transparencia de los procesos electorales, en las instituciones, etcétera. lo cual fácilmente puede dañar a las estructuras económicas, políticas y sociales de un país.

En procesos de transición democrática, la comunicación resulta aún más importante para lograr la noción de transparencia. El ciudadano necesita convencerse de que la información es veraz y comprobable. En el caso de información tendiente a generar una opción de voto, los comicios electorales deben ser llevados a cabo con toda seriedad y apegados a la legalidad vigente, ya que al no hacerlo así se cae irremediablemente en una multiplicación de información irrelevante que oscurece los mismos procesos que trata de promover.

De hecho, en procesos de transición hacia la democracia, la ciudadanía necesita escuchar una y otra vez que la democracia es una posibilidad real. La esencia misma de la transición radica en repetir constantemente que ésta se está llevando a cabo y que la participación ciudadana será tomada en cuenta. Como dice Wolton:

[A]l estar a mitad de camino de la lógica representativa de la opinión pública y de la política, [los medios] defienden la presencia de una lógica del acontecimiento indispensable para no liquidar el sistema político [Wolton, 1992: 197].

Así, los medios de comunicación en su vinculación con la política, asumen una de sus funciones más importantes que es la de articular posiciones estratégicas para los actores involucrados en momentos de coyuntura política. ${ }^{23}$

Ahora bien, la ausencia de mensajes claros como parte del cúmulo de discursos que rigen la política en la actualidad, no sólo cambia las formas y sistemas de representación, sino que también genera nuevos sistemas simbólicos que inciden en los imaginarios colectivos existentes sobre la democracia.

${ }^{23} \mathrm{El}$ papel de los medios ha sido estudiado sobre todo en procesos electorales, pero no con tal amplitud en períodos intermedios o de transición cuya posición resulta menos visible, pero notoriamente impactante. 
Para que el receptor lo considere viable, ese imaginario debe estar constituido esencialmente por la presencia de un futuro posible que puede ser alcanzado a través de la participación. Mientras eso no suceda y en tanto la realidad presentada por los medios de comunicación sea una en la que impere el descrédito y la desconfianza, no será posible generar los espacios de participación ciudadana que el país necesita.

\section{México: la opinión pública de la esperanza perdida}

Más allá de los factores reales que han coadyuvado a la parálisis del gobierno foxista en México (como la constitución de las cámaras sin una mayoría clara que permita dar curso a las iniciativas), están las expectativas del pueblo promovidas en su momento por el candidato, y por los medios.

Hoy los medios mexicanos, fieles a su necesidad de conservar a las audiencias, han retomado la desesperanza de la ciudadanía como bandera y, tomando en cuenta el termómetro de la opinión pública, se han vuelto en contra del presidente para recriminarle que no ha entregado los resultados que había prometido.

La ausencia de una estrategia definida en materia de comunicación política ha proyectado falta de coordinación y liderazgo entre la figura presidencial y los miembros de su gabinete. Los discursos de los funcionarios públicos son, en su gran mayoría, contradictorios o mediocres, lo cual ha proporcionado nueva artillería a la oposición para la crítica de su gestión.

Ante una situación como ésta y sin ninguna posición clara que delimite a una propuesta de otra, la sensación que queda en la ciudadanía es fundamentalmente de caos.

La primera muestra contundente de esa situación, la tuvimos en las pasadas elecciones intermedias del 2003 en donde, según los datos arrojados por algunas encuestas, a pesar de todo el gasto mediático, un buen número de electores optaron por el abstencionismo. ${ }^{24}$ Entre las razones: la desilusión por la gestión actual y la ausencia de propuestas claras de los partidos. Otra de las razones: el predominio de los medios masivos de comunicación y de las industrias culturales sobre formas tradicionales de interacción, la descomposición de casi todas las formas de representación política, sindical y social y la dificultad de encontrar nuevas narrativas cohesionadoras socialmente (García Canclini, en César Cancino, 2003: 32).

A últimas fechas, los medios nos han dado cuenta de la forma en que la política se ha trastocado. Desde los videoescándalos que enfatizan la persis-

${ }^{24}$ Las cifras del Instituto Federal Electoral (IFE), indican que en las elecciones intermedias del pasado 6 de julio del 2003, el índice de abstencionismo estuvo alrededor del $60 \%$. 
tencia de la corrupción en la política interna, los autosecuestros de gobernadores, la renuncia de secretarios de Estado y los autodestapes para una carrera electoral presidencial que todavía no inicia, hasta los errores de la diplomacia mexicana en el caso de Cuba, la política mexicana se ha convertido en un espectáculo. En este circo de tres pistas, la verdad es que salen desfavorecidos todos, no solamente los funcionarios en turno y los miembros de la oposición organizada, sino también los ciudadanos.

De este modo los intercambios de comunicación que vemos entre los diferentes actores sociales y políticos se han vuelto correlativos a la crisis.

Hoy en día es fundamental olvidarnos de la espectacularización de la política y elevar el debate público, no tanto para recuperar la estabilidad política (ya que esa tarea no puede dejársele exclusivamente a los medios de comunicación), sino cuando menos para aminorar la desesperanza. Pese a la violencia, al crimen, a las crisis económicas, la ciudadanía necesita saber que existen posibilidades reales para la continuación de la convivencia social.

Por otra parte, la opinión pública internacional requiere información clara y precisa acerca de lo que ocurre en un país con una posición estratégica tan específica como México. Es importante que nuestro país difunda una imagen positiva respecto de su avance hacia la democracia. Queda muy claro pues, que el papel de la comunicación sigue siendo fundamental; y así lo han reconocido tanto gobernantes, y autoridades electorales como partidos políticos.

Hoy en México los medios tienen una posición muy distinta de la que tenían cuando este país giró hacia el cambio democrático: han logrado una relación diferente con el ejecutivo ${ }^{25}$ lo cual evidencia una posición de peso por parte de los medios, en especial los electrónicos, que inclina claramente la balanza hacia ciertos intereses. Si bien el tránsito a la democracia nos ha llevado de un sistema de medios auténticamente controlado por el Estado a uno más abierto en el cual los medios han comenzado a hacer uso de su libertad de expresión, también es cierto que hemos roto el delicado cerco de la difusión de los asuntos de interés público que llevaba a la discusión y al debate de las ideas, quedándonos simplemente con la publicidad desmedida de la propaganda política.

Así, los medios van definiendo su propia esfera de participación como actores en la arena política pero, a diferencia de los otros, partidos o electorado, no se encuentran en igualdad de condiciones, simplemente porque tienen en sus manos los márgenes de visibilidad de los otros dos.

Ante la actual falta de credibilidad hacia los cuadros gobernantes y frente a las nuevas posiciones de poder informal que están siendo recla-

25 Al lograr la publicación en el Diario Oficial de la Federación de una utilización diferente del antiguo $12.5 \%$ de tiempo destinado al Estado que por ley debían ofrecer los concesionarios de la radio y la televisión. 
madas de manera desigual por ciertos actores en la política, estamos, pues, ante un marco de deslegitimación del poder establecido y de crecimiento irrestricto de ingerencia de las instituciones de medios en la política. Esto socava, sin lugar a dudas, la autoridad del Estado y nos ubica en una nueva dinámica de gestión del poder.

\section{Conclusiones}

Nos encontramos ante un escenario único en la historia de la vinculación entre la política y los medios de comunicación en México. Por un lado, afectando directamente la relación medios gobierno, se encuentran las condiciones reales de los mercados globales de medios que obligan a los sistemas de medios nacionales a responder a las lógicas de producción de mensajes que operan en todo el mundo y, por otro lado, están las condiciones económicas, sociales y culturales específicas de nuestro país.

Las instituciones de medios nacionales ya no responden a las demandas del poder político como antaño, pero tampoco se encuentran coludidas con el gobierno como en épocas pasadas; antes bien, los medios están reaccionando a sus propias agendas y con sus propios intereses desligándose así de un auténtico proceso de participación política responsable. Con el pretexto de la objetividad, los medios no se comprometen, pero se encuentran definitivamente posicionados entre las elites económicas del país y la clase política. Por tanto, lo que observamos es una reconversión de la propia clase política, una lucha por el poder y por el control de la visibilidad en los medios.

Lo anterior está provocando una tensión especial entre la estructura social y las prácticas de consumo de los grupos, además de procesos de reconversión y transformación estatal, en donde ya no es el Estado quien determina los asuntos de la agenda política, sino que son los medios los que toman las riendas de la discusión social.

Ahora bien, los medios por sí mismos tampoco son autónomos. Están sujetos a las condiciones políticas y sociales del modelo histórico que les toca representar, así como a los vaivenes de la tecnología y de las prácticas de comunicación internacionales, por ello no puede conferírseles la responsabilidad de estructurarse en una nueva forma de Estado porque, sea cual sea su discurso frente a la democracia, el hecho es que siempre responderán a intereses particulares y de grupo.

Nuevamente, si recordamos que la democracia es un régimen político cuyo funcionamiento está mediado por los tipos de articulación entre sociedad, sistema político y Estado, encontraremos que los medios de comunicación no pueden sino constituirse, en todo caso, como una parte muy importante de la sociedad, aunque de ninguna manera pueden erigirse en sustitutos del sistema político o de la institución estatal por un 
razón muy sencilla: en una democracia el pueblo elige a sus gobernantes, pero no a sus medios de comunicación y, dado que el Estado ha evadido su responsabilidad en la gestión de una política pública de comunicación, son los medios mismos quienes han marcado la pauta.

Si los medios de comunicación han pasado a ocupar de manera ilegítima el papel del Estado, es porque los propios actores de la política les han conferido ese lugar, pues reconocen que ante la crisis de representación de las instituciones políticas, los medios son los únicos capaces de generar y difundir los grandes discursos aglutinadores de la sociedad.

$\mathrm{El}$ análisis de las formas contemporáneas de la democracia nos obliga a reconocer el papel sustancial de la comunicación. Si bien una ciudadanía informada seguramente será capaz de tomar mejores decisiones respecto de lo que le atañe, la presencia de información excesiva en los medios de comunicación puede ser síntoma de una crisis de representación de las instituciones políticas que, lejos de promover los espacios de reflexión pública, los obstaculice.

Los factores de recomposición de las fuerzas políticas que conducen directamente al establecimiento de patrones democráticos, sociedad, sistema político y Estado existentes en una formación social en un momento histórico determinado, entran, de manera irreversible, en un proceso de recomposición cada vez que aparece un elemento articulador nuevo, bien sea éste un cambio en el modelo de desarrollo establecido, o sean presiones de índole nacional o internacional que moldean de manera diferente la agenda de la discusión social.

En todo caso, es obligación del Estado de recomponerse, de los medios, de asumir una posición mucho más responsable respecto de su participación en el proceso democrático, y de la ciudadanía, de asumir los riesgos de una verdadera democracia deliberativa y buscar a través de la racionalidad y el debate de las ideas, la tolerancia en las distintas alternativas de realidad.

Este modelo debe ser la única opción viable, de otra suerte, será cada vez más difícil buscar la verdadera promesa de la democracia.

\section{Bibliografia}

Aguilar F., Luis (2004), "Gobiernos emproblemados", en Reforma, 28 de abril 28, p. 18. Aguilar Zínzer, Adolfo (2004), "Luz al final del túnel”, en Reforma, 26 de Marzo, p. 19. Balkin, J.M. ( 1998), "How Mass Media Simulate Political Transparency". Disponible en http://yale.edu/lawweb/jbalkin/articles/media01.htm.

Boorstin, Daniel J. (1992), The image. A Guide to Pseudo-events in America, Vintage Books, Random House

Casas Pérez, María de la Luz (1997), "Reflexiones sobre política y comunicación al

final de una era", en Diálogos de la Comunicación, núm. 48.

- (2000), "Imaginarios políticos y comunicación". Texto presentado en la 
reunión de la International Communication Association (ICA), Acapulco, México, junio

- (2003). "Medios de comunicación y sistemas de representación política", ponencia presentada en el XII Encuentro Nacional de Comunicación CONEICC, Guadalajara, México, octubre-noviembre

Castells, Manuel (1999), La era de la información, Siglo XXI.

Cerrutti Guldberg, Horacio (1998), “¿Democracia y proyecto latinoamericano para México?”, en Metapolítica, núm. 7, pp. 483-494.

CIMA Consorcio Iberoamericano de Investigación y Mercadeo (febrero de 2003), Revista Semana de Bogotã, núm. 1086 del 24-02-03, pp. 44 y siguientes, citado en: Javier Darío Restrepó, "La palabra y la democracia", en Reforma, Suplemento Enfoque, 6 de julio de 2003, pp. 16-19.

Fernández Santillán, José (2000), "Democracia en México", en Baca Olamendi, Laura, Judit Bóxer-Liwerant, Fernando Castañeda, Isidro H. Cisneros y Germán Pérez Fernández del Castillo (comps.), Léxico de la Política, FLACSO/SEP-Conacyt/ Heinrich Böll Stiftung/FCE.

Fuentes, Carlos (1998), "El humanismo creativo. La reinvención del tiempo", en Reforma, Revista cultural, Suplemento El Ángel, domingo 13 de diciembre.

García Canclini, Néstor (1998), "La globalización en pedazos: integración y rupturas en la comunicación", en Diálogos de la Comunicación, núm. 51.

- (2003). "La modernidad latinoamericana debe ser revisada", entrevista realizada por César Cancino, Metapolítica, mayo-junio.

Germani, Gino (1962), Política y sociedad en una época de transición, Paidós.

Habermas, Jürgen (1989), Teoría de la acción comunicativa, Taurus.

(1998), Between Facts and Norms: Contributions to a Discourse Theory of Law and Democracy (Studies in Contemporary German Social Thought), MIT Press.

Lozano Rendón, José Carlos (2001), “Medios de información y poder político”, en Mariñez Navarro, Freddy (coord.), Ciencia Política. Nuevos contextos, nuevos desafios, Noriega Editores, 2001.

Luján, Noemí (2002), “Credibilidad y confianza políticas: elementos para un diagnóstico de la cultura política en México", resultados presentados por la Dirección Ejecutiva de Capacitación Electoral del Instituto Federal Electoral en el "Coloquio para el análisis de encuestas nacionales sobre cultura política y prácticas ciudadanas". Disponible en: http://deceyec.ife.org.mx/ credibilidad_confianza.pdf.

Norris, Pippa (2001), "El Involucramiento cívico: México desde una perspectiva comparada". Conferencia magistral impartida en la Secretaría de Gobernación durante el Coloquio para el Análisis de Encuestas Nacionales sobre Cultura Política y Prácticas Ciudadanas, 2001. Disponible en: http:// gobernacion.gob.mx/coloquio/Abs/05\%20Norris.htm.

Pavón, Olivier (2004), "En índice de confianza la policía sale reprobada con 5 puntos; los diputados sacan sólo 4.2: encuesta Mitofsky", en Crónica. Disponible en: http://www.cronica.com.mx/nota.php?idc=12459.

Pipitone, Ugo (1998). "Ensayo sobre democracia, desarrollo, América Latina y otras dudas", Metapolitica, núm. 7 p. 463-482.

Restrepó, Javier Darío (2003), "La palabra y la democracia", en Reforma, Suplemento Enfoque, 6 de julio 
(Sin autor) (2004), "Crisis de credibilidad política paraliza a México", 12 de mayo. Disponible en: http://terra.com/actualidad/articulo/html/act176002.htm

(Sin autor) (2004), "Hay poca credibilidad hacia la política: PRI". El Economista [en líneal. Disponible en http://economista.com.mx/online4.nsf, 1 de junio.

(Sin firma) (2003), "No es la ética, son las finanzas", Etcétera, marzo 18.

Thompson, J. B. (1995), The Media and Modernity: A Social Theory of the Media, Stanford University Press

Touraine, Alain (1992), "Comunicación política y crisis de representatividad", en J.

M. Ferry y D. Wolton et al., El nuevo espacio público, Gedisa, 1992.

Touraine, Alain (1995), ¿Qué es la democracia?, Fondo de Cultura Económica.

Transparencia Mexicana (2003), "Encuesta Nacional de Corrupción y buen Gobierno", Documento disponible en el sitio de Transparencia Mexicana, en http://www. transparenciamexicana.org.mx/documentos/ENCBG\%202003/ Encuesta\%20Nacional\%20 de\%20Corrupcion\%20y\%20Buen\%20Gobierno\% 202003.pdf.

Winocur, Rosalia (2000), "Comunicación Política", en Laura Baca Olamendi, Judit Bóxer-Liwerant, Fernando Castañeda, Isidro H. Cisneros y Germán Pérez 338 Fernández del Castillo (comps.), Léxico de la Política. FLACSO/SEP-Conacyt/ Heinrich Böll Stiftung/FCE.

Wolton, Dominique (1992), "La comunicación política: construcción de un modelo", en J. M. Ferry, Dominique Wolton et al., El nuevo espacio püblico, Gedisa. 